Available online at GSC Online Press Directory

GSC Biological and Pharmaceutical Sciences

e-ISSN: 2581-3250, CODEN (USA): GBPSC2

Journal homepage: https://www.gsconlinepress.com/journals/gscbps

(RESEARCH ARTICLE)

\title{
The biological assessment in pediatric dentistry: A cross-sectional study
}

\author{
Bensouda Sanaa ${ }^{1}$, Boufdil Hind ${ }^{2, *}$, Al jalil Zineb ${ }^{3}$, El mousaid Khadija ${ }^{4}$, Lakrim Rania ${ }^{4}$, Hamza Mouna ${ }^{1}$ and \\ El arabi Samira ${ }^{1}$
}

\begin{abstract}
${ }^{1}$ Professor, Department of Pediatric Dentistry, Faculty of Dentistry, Hassan II, University of Casablanca, Morocco.
${ }^{2}$ MD, resident, Department of Pediatric Dentistry, Faculty of Dentistry, Hassan II University of Casablanca, Morocco.

${ }^{3}$ Specialist, Department of Pediatric Dentistry, Faculty of Dentistry, Hassan II University of Casablanca, Morocco.

${ }^{4}$ MD, Faculty of Dentistry, Hassan II University of Casablanca, Morocco.
\end{abstract}

Publication history: Received on 19 March 2020; revised on 28 March 2020; accepted on 30 March 2020

Article DOI: https://doi.org/10.30574/gscbps.2020.11.1.0070

\begin{abstract}
The biological assessment is a complementary examination, which makes it possible to confirm or to cancel the presence of disorder suspected during the clinical examination. It has an important role and is a necessary step towards to better care. The aim of this study is to determine the biological reports prescribed and consulted by the pedodontic service and to evaluate the practitioners' knowledge of biological reports as well as their training needs. The descriptive cosssectional epidemiological survey was conducted on 35 practitioners. Our population is made up of all residents, specialists and teachers at the Pedodontics Department in Dental Consultation and Treatment Centre in Casablanca. The survey was conducted over a two-month period, from November 2018 to December 2018. The data collection was carried out through a questionnaire. $100 \%$ of practitioners prescribed a biological assessment for children, $62,9 \%$ of the practitioners surveyed have not received any continuing training in biological assessment, $100 \%$ of the practitioners need training to develop their knowledge about biological assessment. In the light of the results, it appears that knowledge of the principle of these tests is therefore essential to prescribe them in a relevant manner and to be able to interpret the results in collaboration with the attending physician. This allows better planning of potentially risky oral health care.
\end{abstract}

Keywords: Biological assessment; Prescription; Interpretation; Children

\section{Introduction}

The practice of dentistry has changed and will continue to change in the future. Dentists are treating more and more medically compromised patients who require a complex management with more difficult dental treatment planning. At the pediatric dentistry department of university hospital of Ibn Rochd Casablanca Morocco, one third of the children consulting have a general condition problem. Among these pathologies we found infectious or hemorrhagic risks that must be taken into consideration before carrying out any act that could lead to bleeding or bacteriemia. In these cases, the biological assessment finds a place, allowing the practitioner to confirm or refute a suspicion of disorders revealed by the interrogation and the clinical examination.

The knowledge of the principle of these tests is therefore essential to prescribe them in a relevant manner so that the results can be interpreted in collaboration with the treating physician. In some cases, a simple request for a biological test can bring to light apathology not recognized suspected by the practitioner after anamnesis and clinical examination.

The knowledge of the indications and the direct impact of the bioassessment on dental care as well as a good interpretation of its values is of great interest in pediatric dentistry. For this reason, a study was conducted on the

\footnotetext{
* Corresponding author: Boufdil Hind
}

Copyright (C) 2020 Author(s) retain the copyright of this article. This article is published under the terms of the Creative Commons Attribution Liscense 4.0. 
prescription of the biological check-up on children at the pediatric dentistry department of the Dental Treatment and Consultation Centre (CCTD), which is a care and training centre that is part of the four University Hospital of Casablanca.

The aim of this study is to assess the knowledge of practitioners concerning the prescription and interpretation of the biological assessment and to determine the training needs of these practitioners.

\section{Material and methods}

This cross-sectional study took place in the pediatric dentistry department of the Dental Treatment and Consultation Centre (CCTD) which is part of the University Hospital of Casablanca, over a period of two months (November 2018 to December 2018). The study targeted residents, specialists and professors in the pediatric dentistry department, and also all the interns assigned to CCTD. A pre-study was carried out beforehand with 15 residents assigned to other departments.

- The data collection was carried out though a questionnaire. It's included four parts :

- Identification of the practitioner : Including sex, age and the training concerning the biological assessment

- The indication of prescription of the biological assessment : it provides information on the different biological tests prescribed by the practitioner

- The interpretation of the biological assessment : this variable allows to determine which test are easily interpreted by the dentist

- Biological assessment training needs: allows to know the source of the practitioner's knowledge and specify whether or not there is a need for training.

Data processing consisted of a quantitative analysis. This analysis was performed using SPSS software at the Laboratory of Epidemiology and Biostatistics of the Faculty of Dentistry of Casablanca.

\section{Results}

The average age of the 35 practitioners was $29.8+/-6.9$, the majority of whom were women (88.6\%). Only $37.6 \%$ had received a continuing education in biological assessment (Table 1).

Table 1 Socio-demographic data

\begin{tabular}{lll}
\hline Variables & $\mathbf{N}$ & $\mathbf{\%}$ \\
\hline Sex & & \\
$\quad$ Female & 31 & 88,6 \\
$\quad$ Male & 4 & 11,4 \\
Professional status & & \\
$\quad$ Interne & 18 & 51,4 \\
Résident & 6 & 17,1 \\
$\quad$ Specialist & 8 & 22,9 \\
$\quad$ Professor & 3 & 8,6 \\
Continuing education & & \\
$\quad$ Yes & 13 & 37,1 \\
$\quad$ No & 22 & 62,9 \\
\hline
\end{tabular}

Concerning the prescription of the biological assessment, all the practitioners questioned stated that they had already prescribed it for their patients. The main tests prescribed it for their patients. The main tests prescribed were the complete blood count (CBC) (100\%) hemostasis assessment (91.4\%), and blood glucose level (91.4\%) (Table 2).

$60 \%$ of our study population believe that their current knowledge allows them to interpret a biological assessment without difficulty, particularly CBC (60\%), hemostasis assessment (54.3\%), and blood glucose level (54.3\%) (Table 3). 
Most of the practitioner's knowledge was acquired during clinical internships (85.7\%). Lectures (82.9\%) and via the internet $(74.3 \%)$. The training received during the university course was considered insufficient to prescribe and interpret a biological assessment. All the practitioners feel the need for additional training through workshops (82.9\%), seminars $(71.4 \%)$ and conferences (62.9\%) (Table 4$)$.

Table 2 Tests prescribed by practitioners

\begin{tabular}{|c|c|c|}
\hline Variables & $\mathrm{N}$ & $\%$ \\
\hline \multicolumn{3}{|c|}{ Complet blood count (CBC) } \\
\hline Yes & 35 & 100 \\
\hline No & 0 & 0 \\
\hline \multicolumn{3}{|c|}{ Hemostasis assessment } \\
\hline Yes & 32 & 91,4 \\
\hline No & 3 & 8,6 \\
\hline \multicolumn{3}{|c|}{ Sedimentation rate } \\
\hline Yes & 9 & 25,7 \\
\hline No & 26 & 74,3 \\
\hline \multicolumn{3}{|c|}{ Blood glucose level } \\
\hline Yes & 32 & 91,4 \\
\hline No & 3 & 8,6 \\
\hline \multicolumn{3}{|c|}{ Urea-creatinine } \\
\hline Yes & 3 & 8,6 \\
\hline No & 32 & 91,4 \\
\hline \multicolumn{3}{|c|}{ Transaminase } \\
\hline Yes & 12 & 34,3 \\
\hline No & 23 & 65,7 \\
\hline \multicolumn{3}{|l|}{ Serology } \\
\hline Yes & 19 & 54,3 \\
\hline No & 16 & 45,7 \\
\hline \multicolumn{3}{|c|}{$\begin{array}{l}\text { Tests for the detection of bacterial } \\
\text { pathologies }\end{array}$} \\
\hline Yes & 6 & 17,1 \\
\hline No & 29 & 82,9 \\
\hline \multicolumn{3}{|c|}{ Allergy tests } \\
\hline Yes & 1 & 2,9 \\
\hline No & 34 & 97,1 \\
\hline \multicolumn{3}{|c|}{ INR, viral load } \\
\hline Yes & 3 & 8,6 \\
\hline No & 32 & 91,4 \\
\hline
\end{tabular}

Table 3 Tests that are easily interpreted by the practitioner

\begin{tabular}{lll}
\hline Variables & $\mathbf{N}$ & $\mathbf{\%}$ \\
\hline Complet blood count (CBC) & & \\
Yes & 21 & 60 \\
No & 14 & 40 \\
Hemostasis assessment & & \\
Yes & 19 & 54,3 \\
No & 16 & 45,7 \\
Sedimentation rate & & \\
Yes & 10 & 28,6 \\
No & 25 & 71,4 \\
\hline
\end{tabular}


Bensouda et al. / GSC Biological and Pharmaceutical Sciences, 2020, 11(01), 018-023

Blood glucose level

Yes

19

54,3

No

16

45,7

Urea-creatinine

Yes

7

20

No

28

80

Transaminase

Yes

9

25,7

No

26

74,3

Serology

Yes

12

34,3

No

23

65,7

Tests for the detection of bacterial pathologies

Yes

8

22,9

No

27

77,1

Allergy tests

Yes

6

17,1

No

29

82,9

INR, viral load

Yes

1

2,9

No

34

97,1

Table 4 Sources of knowledge and training needs

\begin{tabular}{lll}
\hline Variables & $\mathbf{N}$ & $\mathbf{\%}$ \\
\hline Origin of knowledge & & \\
Lecture course & 29 & 82,9 \\
Clinical internship & 30 & 85,7 \\
Internet & 26 & 74,3 \\
Library & 10 & 28,6 \\
Means of training & & \\
Seminars & 25 & 71,4 \\
Workshops & 29 & 82,9 \\
Conferences & 22 & 62,9 \\
University degrees & 18 & 51,4 \\
Others & 4 & 11,4 \\
\hline
\end{tabular}




\section{Discussion}

The study was conducted on a population of 35 practitioners, the majority of whom was female (88.6\%). This percentage is explained by the dominance of women in the public medical department. In France, women account only for $34 \%$ of practitioners over 50 years, on the other hand, they account for $44 \%$ of those under 50 years. This percentage will continue to increase in the future to reach $45 \%$ in $2030[1,2]$.

The mean age of the study populaton in the Department of Pediatric Dentistry was $29.7+/-6.8$ years. This is due to the fact that most of the practitioners in our sample were interns and residents in their 30's. However, in France, far from the university, the age pyramid of dentists shows a strong ageing of the profession, the average age of the practitioners listed in 2006 is 47 , and $44 \%$ of them were over fifty years old [1,2].

$37.1 \%$ of the practitioners said they had taken part in continuing education in biological assessment, in contrast to other countries where continuing education plays a major role in the university cursus of practitioners, with a rate of 60 to $75 \%$ [3]. Indeed, the courses dealing with the biological assessment do not take an individual place, but can be found in other disciplines such as patients at risk in pediatric and surgical dentistry. It can be said that the low percentage of practitioners who have received continuing education in biological assessment can be explained by the lack of interest of the practitioners.

All the practitioners had already prescribed a biological assessment, which reflected the diversity of clinical situations encountered by the practitioners within the department. According to a study carried out on « risk patients in Pediatric Dentistry at the CCTD », one third of the patients consulting the department are patient at risk, hence the importance of sufficient knowledge of clinical examination [4].

The practitioners questioned prescribed 9 tests, the most frequent were the CBC (100\%), hemostasis assessment (94.3\%). This is because the majority of children attending the CCTD had either an infectious or bleeding risk or both. Nevertheless, other less clinical situations may indicate the prescription of other biological tests (blood glucose level of diabetes, creatinine and urea for nephropathy...), hence the importance of mastering biological test other than the CBC and hemostatic tests $[3,4]$.

$60 \%$ of the practitioners questioned considered that their current knowledge in the biological assessment without difficulty, particularly when it involves a CBC (60\%), a hemostasis assessment (54.3\%) and a blood glucose level $(53.3 \%)$. The results of our survey showed that half of the practitioners could not interpret the assessment individually. This may be due to a lack of interest in further training.

It's obvious that the dentist must contact the attending physician in order to get better information about the patient's state of health. Nevertheless, a good interpretation of the biological assessment will allow the practitioner to better control the patient's care, to save time and for better communication with the physician [5].

$74.3 \%$ of our population relied jointly on their previous knowledge and the standards provided by the medical analysis laboratory. This underlines the importance of making available other means of interpretation such as « guideline » to facilitate practice [6].

Practitioners' knowledge of biological assessment was acquired mainly in lectures (82.9\%). A study carried out in France showed that continuing education was the main source of training for the dentist, followed by books, lectures, professional meeting and then documentation [2].

In order to improve their knowledge, all practitioners felt the need for additional training, mainly though workshops (82.9\%). According to a study, workshops came first with $32 \%$ ahead of congresses (25\%) and conferences $(20 \%)$. Courses and seminars came last. This can be explained by the fact that the practitioners found these methods equally formative but a little boring [2].

\section{Conclusion}

The knowledge of biological assessment is essential, they remain a precious tool for the dentist, allowing him on the one hand the early detection of some pathologies with oral manifestations and on the other hand a good planning of oral care. 
- In view of the results of this study, which highlight needs in practitioners' knowledge of biological assessment, we see that is interesting to offer some suggestions :

- Schedule a specific lecture on the biological assessment during the university course of dentists and during their residency with a sufficient number of hours

- Organize training seminars

- Synchronize in a suitable way the lecture and clinical teaching

- Continuing medical education (University degree, subscription to a scientific journal, participation in congresses...).

\section{Compliance with ethical standards}

\section{Acknowledgments}

The authors acknowledge the contribution of the staffs of Pediatric Dentistry department and Epidemiology and Biostatistics department of Faculty of Dentistry Casablanca.

\section{Disclosure of conflict of interest}

We have no conflicts of interest to disclose.

\section{References}

[1] Elsa R and Julie M. (2007). Ministry of Health, Youth and Sports, The profession of dental surgeon: current characteristics and developments, A qualitative study, MSJS, 6-7.

[2] Charpiot E, Medical emergencies in the dental office: current data and survey of dental surgeons in Doubs, University of Lorraine Faculty of Odontology of Nancy.

[3] Rerhrhaye M. (2010). Biological assessment in odontostomatology: interest and interpretation, Act OdontoStomato, 250, 117-135,

[4] High health authority. (2011). Technology Assessment Report: Biology of Haemostasis Abnormalities, HAS, 6-7.

[5] Belery C. (2011). How to prescribe additional preoperative exams in 2010. Med Buc Chir Buc, 17, 211-224.

[6] Scully C. (2014). Scully's medical problems in dentistry, Seventh edition, 19 (3), 179-88.

\section{How to cite this article}

Bensouda S, Boufdil H, Al jalil Z, El mousaid K, Lakrim R, Hamza M and El arabi S. (2020). The biological assessment in pediatric dentistry: A cross-sectional study. GSC Biological and Pharmaceutical Sciences, 11(1), 18-23. 